\title{
Reformation of VET and demands on teachers' subject knowledge: Swedish vocational teachers' recurrent participation in a national CPD initiative
}

Susanne Köpsén and Per Andersson

The self-archived postprint version of this journal article is available at Linköping University Institutional Repository (DiVA):

http:/ / urn.kb.se/ resolve?urn=urn:nbn:se:liu:diva-123503

N.B.: When citing this work, cite the original publication.

Köpsén, S., Andersson, P., (2017), Reformation of VET and demands on teachers' subject knowledge: Swedish vocational teachers' recurrent participation in a national CPD initiative, J ournal of Education and Work, 30(1), 69-83. https:// doi.org/ 10.1080/13639080.2015.1119259

Original publication available at:

https:/ / doi.org/ 10.1080/13639080.2015.1119259

Copyright: Routledge

http:// www.routledge.com/ 


\title{
Reformation of VET and demands on
}

\section{teachers' subject knowledge \\ - Swedish vocational teachers' recurrent participation in a national CPD initiative}

\author{
S. Köpsén and P. Andersson
}

\begin{abstract}
This study investigates continuing professional development (CPD) of vocational teachers, with a focus on recurrent participation. Vocational teachers need to be competent as teachers and in relation to their vocational teaching subject. Reformation of Swedish vocational education in order to strengthen the working-life connection imposes demands on teachers to have up-to-date knowledge about the vocations related to their vocational subjects. To support the reform, vocational teachers have been offered to participate in a new national CPD initiative targeting their vocational competence. The study concerns participation in this initiative. Drawing on a socio-cultural perspective, vocational teachers' CPD implies boundarycrossing between school and working-life. Theory concerning adults' participation in education is considered relevant to understand conditions for such boundary-crossing, and learning, among vocational teachers. The article specifically investigates patterns in vocational teachers' recurrent participation, which is expected to clarify the factors influencing further participation in professional development. The strongest predictor of recurrent participation, when adjusting for the influence of other factors, is the type of municipality that the teacher comes from, with low populated municipalities having the lowest likelihood of participation. Furthermore, recurrent participation is more likely by participating teachers from adult education or from privately owned schools, and by male teachers.
\end{abstract}

\section{Introduction}

There is a demand to strengthen the quality of Swedish vocational education and its connection to working life, and in 2011 a reformation of vocational education at upper secondary school was implemented (Ministry of Education 2009). The reformation imposes demands on vocational teachers to be up to date and knowledgeable about their teaching subject. We see vocational teacher professionalism as a kind of dual professionalism, and drawing on a sociocultural perspective (e.g. Lave and Wenger 1991; Wenger 1998) we would say a vocational teacher identity is based on a teacher identity as well as a vocational identity. That is, the vocational teachers need to have the competence to fully participate in a community of teaching as well as the competence to fully participate in a specific community of vocational practice (Fejes and Köpsén 2014). For vocational teachers, the reform policy refers to having an up-to-date vocational identity that is related to the teaching subject. Discussing dual professionalism, this article concerns the continuing professional development (CPD) that targets vocational teachers' professionalism related to a specific work-life community of vocational practice. Fejes and Köpsén (2014) found in a small-scale study of Swedish vocational teachers that many of the interviewees did not consider themselves competent in relation to contemporary vocational practice and they talked of barriers to retaining and developing their vocational knowledge and skills. Conditions for vocational teachers' CPD are different from other groups of teachers as their subject competence is situated in a vocational work-life community of practice. Moreover, most Swedish vocational teachers work full-time as teachers and thus spend their work time in school. The vocational teachers' competence and CPD in the teaching subject is just as important as for academic teachers; however, it is not so often recognised or examined (Parsons et al. 2009). This article is meant to contribute by examining Swedish vocational teachers' participation in CPD activities that target their vocational knowledge and skills in relation to the vocational subject. More specifically, we examine their recurrent participation in CPD. 


\section{Reformation and a national initiative of CPD}

There are various national educational traditions and cultures of vocational education and training (Billett 2011; Brockmann et al. 2008; Brockmann, Clarke, and Winch 2008; Grollmann 2008). Swedish vocational education was reformed in 2011 and the current goals of vocational education emphasise knowledge-based learning outcomes that are related to employability (Ministry of Education 2009). This is a shift from a primarily school-based vocational education, which has the goal of multi-dimensional development of the student as a citizen as well as an employee. The amount of vocational training has increased at the expense of general courses, and its students will no longer be formally qualified for further studies at university level. It has been argued that this change of policies could be seen as not any longer giving all social classes equal access to an equivalent education (Nylund 2013). However, to support the development of students' employability, the industries and labour representatives have been given more influence in the planning of education programmes and examination of students. Furthermore, to stress the required connection to work life, a pathway of apprenticeship, with at least $50 \%$ of the time spent in the working life, has complemented the normal pathway with 15 weeks of students' placements in working life during the three-year vocational programmes. The reformation and the emphasis of work-based learning and employability have increased the demand for vocational teachers to keep up with the current vocational identity and to remain knowledgeable in their vocational subject. However, despite the policy initiatives to strengthen the quality of vocational education, Swedish vocational teachers no longer need formal teaching qualifications whereas competence in teaching is viewed as a complement. Considering vocational teachers' dual professionalism, the current policy of vocational education primarily emphasises the teachers' vocational competence. Thus, in view of the new requirements the issue of vocational teachers' CPD has been more recognised - and especially the development of vocational competence.

To support the reform of Swedish vocational education there is a new national initiative of CPD for vocational teachers, which target their special needs and demands (Swedish National Agency of Education 2014b). The CPD initiative targets vocational teachers' professionalism related to their vocational subject. In other words, the CPD activities concern the teachers' vocational identity related to a specific community of vocational practice. The initiative in which the Ministry of Education provides financial support, offers opportunities for vocational teachers to participate for a period of two weeks in the vocational, work-life community of practice of their teaching subject, or in other activities related to their vocational subject. Moreover, it is possible for the teachers to participate in the initiative multiple times. The opportunity to participate in this initiative of CPD has only existed since autumn 2012, with one application round each semester. Thus, it is not yet possible to know if it is a success. However, Andersson and Köpsén (2015) have examined the vocational teachers' participation in this new initiative and have found variations of participation in relation to vocational programmes, geographical locations and vocational teachers' age. Furthermore, there are more registered opportunities of participation than individuals, which means that there are vocational teachers that have participated more than once. However, these recurrences were not examined. In this paper, we intend to further develop knowledge about the national initiative to support vocational teachers' CPD in relation to their vocational identity, i.e. their vocational subject, and we will particularly examine the vocational teachers' recurrent participation.

\section{CPD for vocational teachers}

There are various national recognitions and demands of CPD for vocational teachers. Vocational teachers are a heterogeneous group of teachers, whose qualifications and forms of employment differ (e.g. Grollmann 2008; Misra 2011; Parsons et al. 2009). Accordingly, the views on vocational teachers' professionalism vary (Bathmaker and Avis 2005; Fejes and Köpsén 2014; Gleeson and James 2007) as do policies and strategies for vocational teachers' CPD. Vocational teachers are expected to have qualified work-life experience within their teaching subject, but the formal requirements are often less stringent than those of academic teachers. Moreover, the paths of preparation for the teaching task vary. A model of in-service training as part-time participation in teacher training is often used for new vocational teachers to develop their teaching competence (e.g. Bound 2011; Lucas and Unwin 2009; Parsons et al. 2009). However, only a limited amount of research has been found concerning CPD that addresses vocational teachers' competence related to their vocational identity and teaching subject. 
In Finland, the dual vocational teacher professionalism, particularly concerning the teachers' work-life experience and vocational competence, is an issue of concern. The Finnish National Board of Education has created two continuing training programmes for vocational teachers, one of which concerns studies to increase the vocational teachers' competence in the world of work (Frisk 2014; Opetushallitus 2014). In an investigation of vocational teachers' participation in so-called working periods, vocational teachers developed up-to-date knowledge about working life and initiated various changes in vocational education, such as developing teaching and learning materials (Eerola 2007). Several vocational teachers took part more than one working period. However, some vocational teachers did not wish to participate in working periods due factors such as lack of knowledge of contemporary working life, difficulties finding replacement teachers and restrictions in school schedules and teachers' working hours.

Furthermore, Lloyd and Payne (2012) conducted a small-scale comparative study of CPD for vocational teachers in England, Wales and Norway. In England and Wales, there are well-established opportunities for vocational teachers to upgrade their craft skills, partially dependent on a requirement of 300-h a year of 'hands-on' CPD. In Norway, the conditions of vocational teachers' CPD are variable and flexible. However, the opportunities to keep up with their trade are rather limited. This is due, among other things, to a lack of replacement teachers and the fact that Norwegian vocational teachers have permanent employment and work full time - in contrast to English and Welsh teachers, who work part time in temporary employment. In Australia, vocational teachers' CPD is a topic in an ongoing debate about vocational education. In investigations of the quality of vocational teaching, the dual professionalism of vocational teachers was stressed (Wheelahan and Moodie 2010). The investigations include proposals for how to strengthen the quality of teaching, including programmes for Australian vocational teachers' CPD. As mentioned above, Fejes and Köpsén (2014) found in interviews with Swedish vocational teachers that many of them did not maintain an up-to-date vocational identity. The importance of vocational teachers' participation in their former occupational practice in order to retain and develop their competence in relation to their vocational subject was shown. However, most Swedish vocational teachers have a full-time employment position in school and thus, various constraints were found to restrict participation in their former occupational practice, e.g. lack of support from management and lack of replacement teachers.

Andersson and Köpsén (2015) examined Swedish vocational teachers' participation in the abovementioned new initiative of CPD for vocational teachers (Swedish National Agency of Education 2014b).

The initiative gives teachers the opportunity to develop their vocational competence through participation in a specific work-life community of practice or through other activities related to their vocational subject. Andersson and Köpsén (2015) showed that almost 10\% of the Swedish vocational teachers at upper secondary level have taken the opportunity of developing their work-life competence in this initiative. The results show that male teachers are slightly over-represented in participation, and vocational teachers employed at public schools are significantly over-represented, compared to the whole population of Swedish vocational teachers. However, participation rates vary in relation to vocational programmes, geographical location and vocational teachers' age, and the findings indicate some differences that can be discussed in relation to institutional and situational factors. There was an over-representation of participation in highly populated municipalities and under-representation in the large city areas, which may indicate situational factors facilitating or hampering movement between the practice of school and the practice of work. These factors could include having or not having relationships with the workplaces and familiarity with the workers, which may make arranging a placement easier or more difficult. Furthermore, the highest rates of vocational teachers' participation in the CPD initiative in regard to vocational areas were found for teachers representing the vocational areas of Service and Vehicles. This may indicate the importance of institutional factors such as the type of work-place communities of practice and opportunities to access them. It is probably easier to obtain access to the practices of restaurants, hotels, shops, road carriers and garages than to communities of practice that are bound by more safety regulations and strict demands for certificates and permissions. This could be a barrier to boundary-crossing and access to workplaces in, e.g. manufacturing, process industries and practices of electricity and energy, which may explain the under-representation of vocational teachers from the area of technology. Notably, the vocational area of construction is generally under-represented in participation in this new initiative of CPD. Furthermore, over-representation of the 'middle' and largest age group (46-55 years) poses questions concerning CPD of younger and older teachers. 
The new initiative for CPD for vocational teachers could be seen as an opportunity for participation in 'education' or 'training'. As the vocational teachers' CPD takes place outside the school where they are teaching, there will be a matter of choosing to participate in another community of practice with the aim of professional development. Thus, theory concerning adults' participation in education is considered relevant when it comes to conditions for learning among vocational teachers (Cross 1981). As discussed by Andersson and Köpsén (2015), situational and institutional factors as well as individual dispositions may influence vocational teachers' participation in CPD. However, the recurrent participation in the CPD was not examined. Investigations show that adults with higher levels of initial education are more likely to participate in adult education than those with lower levels (Desjardins 2015). Consequently, recurrent participation in the initiative of CPD for vocational teachers is seen not only as interesting per se, but also as indicating a higher likelihood of continuing participation in professional development activities in the longer term. Thus, an analysis of recurrent participation in CPD could clarify influencing factors for further participation and professional development.

\section{The aim}

The aim of the present paper is to examine vocational teachers' recurrent participation in the new national initiative of CPD. The article specifically investigates the pattern of vocational teachers' recurrent participation in the offer of CPD. The research question is:

- How do the vocational teachers who cross the boundaries between the community of school and community of work life and recurrently participate in the CPD programme differ from those who have only participated once?

\section{Theoretical frame}

A sociocultural perspective on practice, identity and learning (Lave and Wenger 1991; Wenger 1998) is employed for analysing our findings. From this perspective, the situated character of knowledge is essential. Knowledge and skills that are related to a vocational subject in school are situated in a specific community of practice, i.e. a vocational practice. Thus, to teach the vocational subject, vocational teachers should have a vocational identity related to this specific subject. That means having the knowledge and skills of the contemporary main tasks of the vocational or occupational practice. Boundary-crossings between the occupational practices and the practice of school are significant for vocational teachers' development of their dual professional knowledge, and particularly the vocational identity related to occupational practices.

In academic terms, Swedish vocational teachers with their practically oriented vocational subject knowledge are usually 'low skilled' compared to other teachers. Therefore, theories concerning (lowskilled) adults' participation in education and training are relevant in this study of participation in CPD. The vocational subject teachers' CPD takes place outside of the school where they teach, i.e. in the work life where their vocation is practised. Therefore, participating in CPD is a matter of choosing to participate in an additional community of practice and so there may be 'barriers' to their participation. Cross (1981) describes three main types of such barriers. Firstly, there are institutional barriers. These concern institutional conditions, where the national initiative of vocational teachers' CPD in itself is an institutional effort to support vocational teachers' participation in 'education'. Other institutional barriers or efforts that may influence their opportunities to participate and interest in participating in CPD include varying conditions across vocational areas and between public and private schools. Secondly, there are situational barriers, which are related to individual life situations, and important factors can include age, sex and geographical location. Thirdly, there are dispositional barriers, which concern individual dispositions or motivation towards participation. Here, influential factors may concern the teacher identity vs. the vocational identity. However, the register data employed in the current study do not involve information on dispositional barriers as related to individual dispositions and motivations for participating in the national initiative for CPD. Therefore, this type of barrier is not included here.

\section{Context}

The study concerns Swedish vocational teachers at upper secondary schools for young people aged 16-20 years and in municipal adult education at upper secondary level. Swedish vocational education at upper secondary level is regulated by a curriculum, and municipally owned public schools typically 
arrange this education, although the number of private schools has increased during the last few years. Vocational education is organised into 12 national three-year programmes, and a few similar local programmes target small vocational areas.

About 25\% (approximately 9850) of all teachers at upper secondary level are vocational subject teachers who are teaching in vocational programmes and responsible for two-thirds of the specific vocational education. Within this population of vocational teachers, $90.5 \%$ teach at upper secondary schools and 9.5\% teach adult education (Swedish National Agency of Education 2014a, 2014b). In the autumn semester of 2013, 8913 vocational subject teachers were employed - full time or part time - at Swedish upper secondary schools. (There are no exact numbers available for vocational adult education.) Statistics show that $37.5 \%$ of the teachers were women and $62.5 \%$ were men. Altogether, their full- or part-time positions were equivalent to 7109 full-time positions. Furthermore, their average age was 49 years.

It is notable that Swedish upper secondary education includes many publicly funded but privately owned 'free' upper secondary schools and providers of adult education. As a measure for comparison, there are approximately 107,000 pupils in the vocational programmes at upper secondary schools, and $27.1 \%$ of them study in privately owned schools (Swedish National Agency of Education 2014a). We have not found any comparable measures for vocational adult education; however, in 2012, 39.7\% of all participants in municipal adult education at upper secondary level (including vocational education) were studying on a course arranged by a private provider (Swedish National Agency of Education 2014a). (It should be noted that the 'privately' owned schools include schools that are organised as companies where municipalities could be among the owners).

\section{Methodology}

This study is based on register data on participation in the above-mentioned national initiative for CPD (Swedish National Agency of Education 2014b). In this paper, we analyse vocational teachers' recurrent participation in this initiative. The opportunity for schools to apply for financial support from the National Agency of Education for their teachers to participate in this CPD initiative has been available since autumn 2012. The current study is based on vocational teachers' participation related to four application rounds. The data were provided by the Swedish National Agency of Education. The findings on participation in the CPD initiative concern the distributions of participating vocational teachers in terms of sex, age (reached during the first year of participation), publicly vs. privately owned schools, upper secondary school vs. adult education, type of municipality of teaching institution and vocational area.

\section{Merged variables}

One aspect that is covered in the analysis is the geographical dimension, i.e. the type of municipality in which a vocational teacher works. Here, we began with an established categorisation of Swedish municipalities that identifies 10 groups or types among the 290 municipalities (Statistics Sweden 2011, 14). However, to identify significant differences in the regional dimension, we merged the 10 groups into the following 4 broader groups of municipalities, with different geographical pre-conditions: The main large city areas, the other large city areas, high-populated municipalities and low-populated municipalities. ${ }^{1}$ In one comparison, we also merge the high- and low-populated municipalities into a category of all other municipalities, to make it possible to identify significant differences (avoiding the risk of obtaining too low expected values, which would make it impossible to apply the chi-square test).

In the analysis, we also compare six vocational areas that vocational education at upper secondary level targets. We identified these areas from the twelve national vocational programmes and two local programmes that were represented in the material. The six areas are as follows: Care, Construction, Practical-aesthetical programmes, Service, Technology and Vehicles. ${ }^{2}$ Finally, the variable of age was Categorized into the following four age groups: $\leq 35,36-45,46-55$ and $56 \leq$.

\section{Analysis}

The explorative analysis includes comparisons within the current data concerning the variables sex, type of municipality and vocational areas. A chi-square test was applied as a test of independence of distributions in cross tables. Finally, a binary logistic regression analysis was applied to identify the 
relative influence of the different categories of the variables, while controlling for the effects of other variables. Here the results are presented as odds ratios, i.e. the likelihood of recurrent participation in one category, as compared to a reference category. In the model, the categories with the lowest likelihood of recurrent participation were chosen as reference categories, which mean that all odds ratios are above 1, i.e. the likelihood is higher than for the reference category. Only those variables that proved to have a significant influence in the logistic regression were included in the presented model. In addition to the variables presented above, this analysis also included a variable defining the semester for the first occasion of participation. This is crucial for the opportunity of recurrent participation in a study covering four semesters, as an early first occasion of participation means much more time for recurrent participation than a late first participation, and thus this variable has to be controlled for. The IBM software SPSS 22.0 was used for the analyses.

The register data contain information on 981 participants. In a few cases, information is missing for one or more variables. The numbers of missing cases in the variables used in the analysis are as follows: 12 missing cases for type of municipality; 21 missing cases for participants' age, and concerning upper secondary school/adult education; and 38 missing cases concerning the vocational area. The numbers of missing cases are considered low and are not expected to have a significant influence on the conclusions of the study.

In the analysis, we also make comparisons with the results of the prior study (Andersson and Köpsén 2015). Here, it should be noted that identified over- and under-representations of participation among different categories of teachers, referred to from that study, are related to the distribution in the whole population of vocational teachers.

\section{Findings}

Here we will present our findings in the examination of vocational teachers' participation in the national initiative of CPD focusing their recurrent participation. We will start by presenting the distribution of recurrent participation, according to vocational teachers' sex, age and geographical and vocational areas. After that, we will focus on the participants that participated recurrently; firstly considering the relationship between sex and municipality, secondly, the relationship between vocational area and municipality and finally, the impact of various variables on the likelihood of recurrent participation.

In total, 981 vocational teachers participated in this CPD initiative during the first two years, i.e. approximately $10 \%$ of the population of vocational teachers in Sweden (see Context). Most of them -812 vocational teachers - participated in one activity, normally a workplace placement for at least two weeks. (More exactly, 594 teachers only participated through a placement, and 218 only did some other type of CPD activity.) However, there were 169 teachers who participated more than once, from twice up to seven times, and the focus of this study is this recurrent participation, and the similarities and differences between teachers with recurrent participation and the other participating vocational teachers. Here, it should be noted that in the present analysis, we do not differentiate between participation in terms of a workplace placement and other CPD activities related to the vocational subject.

\section{Occurrence of recurrent participation}

In the following we will make comparisons between those vocational teachers that participated once and those who participated recurrently. We will show the distributions according to type of school and education, sex and age, and finally geographical location and vocational area. 
Table 1. Recurrent participation among vocational teachers from privately and publicly owned schools/providers.

\begin{tabular}{lcccc}
\hline & & \multicolumn{2}{c}{ Recurrent participation } & \multirow{2}{*}{ Total } \\
\cline { 3 - 4 } & & No & Yes & 89 \\
Private schools & $N$ & 69 & 20 & 100.0 \\
Public schools & $\%$ & 77.5 & 22.5 & 892 \\
Total & $N$ & 743 & 149 & 100.0 \\
& $\%$ & 83.3 & 16.7 & 981 \\
\hline
\end{tabular}

Note: A chi-square test shows that differences are not significant.

Table 2. Recurrent participation among vocational teachers from adult education and upper secondary school.

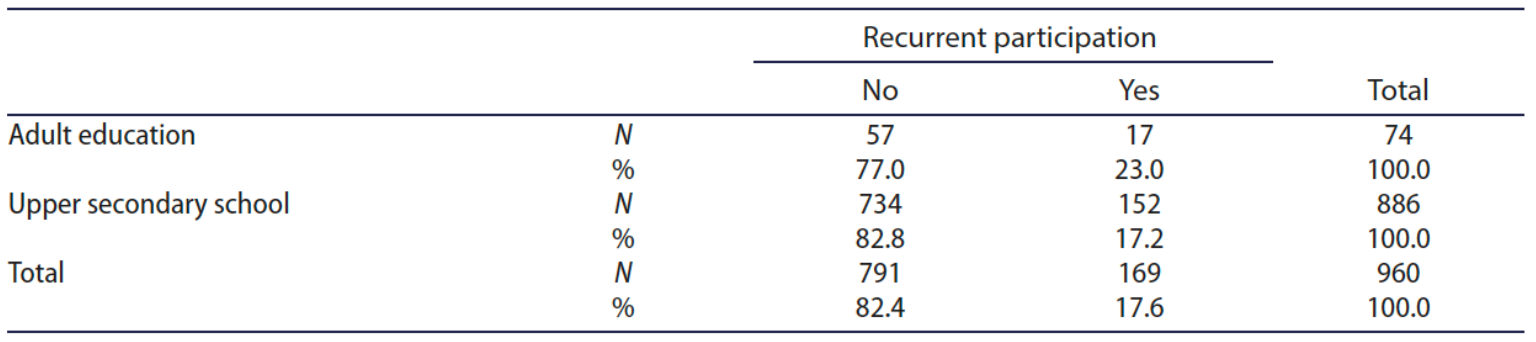

Note: A chi-square test shows that differences are not significant.

Table 3. Recurrent participation among male and female vocational teachers.

\begin{tabular}{|c|c|c|c|c|}
\hline & & \multicolumn{2}{|c|}{ Recurrent participation } & \multirow[b]{2}{*}{ Total } \\
\hline & & No & Yes & \\
\hline \multirow[t]{2}{*}{ Male } & $N$ & 483 & 121 & 604 \\
\hline & $\%$ & 80.0 & 20.0 & 100.0 \\
\hline \multirow[t]{2}{*}{ Female } & $N$ & 329 & 48 & 377 \\
\hline & $\%$ & 87.3 & 12.7 & 100.0 \\
\hline \multirow[t]{2}{*}{ Total } & $N$ & 812 & 169 & 981 \\
\hline & $\%$ & 82.8 & 17.2 & 100.0 \\
\hline
\end{tabular}

Note: A chi-square test shows that differences are significant, $p<.01$.

Table 4. Recurrent participation among vocational teachers in different age groups.

\begin{tabular}{lcccc}
\hline & & \multicolumn{2}{c}{ Recurrent participation } & Total \\
\cline { 3 - 4 } & & No & Yes & 72 \\
\hline 35 & $N$ & 55 & 17 & 100.0 \\
$36-45$ & $\%$ & 76.4 & 23.6 & 198 \\
& $N$ & 166 & 32 & 100.0 \\
$46-55$ & $\%$ & 83.8 & 16.2 & 383 \\
& $N$ & 311 & 72 & 100.0 \\
$56 \leq$ & $\%$ & 81.2 & 18.8 & 307 \\
\multirow{2}{*}{ Total } & $N$ & 259 & 48 & 100.0 \\
& $\%$ & 84.4 & 15.6 & 960 \\
& $N$ & 791 & 169 & 100.0 \\
\hline
\end{tabular}

Note: A chi-square test shows that differences are not significant.

\section{Type of school and education}

As mentioned, typical of Swedish upper secondary education is the high number of privately owned schools. However, this is not reflected in the overall participation in this initiative, where vocational teachers from publicly owned schools are over-represented (Andersson and Köpsén 2015). However, when we look at the pattern of recurrent participation, there is a difference that is worth noting. There is actually a slightly higher proportion of vocational teachers from privately owned schools who have participated more than once (even if the difference is not significant) (Table 1). 
Vocational adult education in Sweden is certainly not as extensive as vocational education in upper secondary school, and this is also reflected in the overall participation in the CPD initiative. The distribution of participation between adult education and upper secondary school does not differ significantly from the distribution of the population of vocational teachers (Andersson and Köpsén 2015). However, when it comes to the rate of recurrent participation, we can see that it is slightly - but not significantly - higher for teachers in adult education (Table 2).

\section{Sex and age distribution}

Furthermore, we can see (Table 3) that there is a significant difference between recurrent participation levels of male and female vocational teachers. Male teachers show a pattern of significantly higher recurrent participation than female teachers. It should be noted that there also is a small overrepresentation of male vocational teachers in the whole group of vocational teachers participating in the CPD initiative (Andersson and Köpsén 2015).

We have also analysed the possible differences between age groups of the returning vocational teachers. Age is defined as age reached during the first year of participation. However, the existing differences (Table 4) are not significant, even though we can see that the youngest age group $\leq 35$ has a pattern of slightly more recurrent participation than the older age groups. Andersson and Köpsén (2015) show that the middle-aged vocational teachers are over-represented among the participants of the CPD initiative, but notably, they do not participate recurrently to any higher degree than other age groups.

Table 5. Recurrent participation among vocational teachers from different types of municipalities.

\begin{tabular}{|c|c|c|c|c|}
\hline & & \multicolumn{2}{|c|}{ Recurrent participation } & \multirow[b]{2}{*}{ Total } \\
\hline & & No & Yes & \\
\hline \multirow[t]{2}{*}{ Three large city areas } & $N$ & 167 & 32 & 199 \\
\hline & $\%$ & 83.9 & 16.1 & 100.0 \\
\hline \multirow[t]{2}{*}{ Other large city areas } & $N$ & 249 & 60 & 309 \\
\hline & $\%$ & 80.6 & 19.4 & 100.0 \\
\hline \multirow[t]{2}{*}{ Highly populated municipalities } & $N$ & 277 & 67 & 344 \\
\hline & $\%$ & 80.5 & 19.5 & 100.0 \\
\hline \multirow[t]{2}{*}{ Low-populated municipalities } & $N$ & 107 & 10 & 117 \\
\hline & $\%$ & 91.5 & 8.5 & 100.0 \\
\hline \multirow[t]{2}{*}{ Total } & $N$ & 800 & 169 & 969 \\
\hline & $\%$ & 82.6 & 17.4 & 100.0 \\
\hline
\end{tabular}

Note: A chi-square test shows that differences are significant, $p<.05$.

Table 6. Recurrent participation among vocational teachers from different vocational areas.

\begin{tabular}{lcccc}
\hline & & \multicolumn{2}{c}{ Recurrent participation } & Total \\
\cline { 3 - 4 } Vocational area & $N$ & No & Yes & 168 \\
\hline Care & $N$ & 140 & 28 & 100.0 \\
Construction & $N$ & 83.3 & 16.7 & 90 \\
Practical-aesthetical & $\%$ & 71 & 19 & 100.0 \\
& $N$ & 117 & 21.1 & 128 \\
Service & $\%$ & 91.4 & 11 & 100.0 \\
Technology & $N$ & 175 & 3.6 & 211 \\
& $\%$ & 82.9 & 17.1 & 100.0 \\
Vehicles & $N$ & 126 & 36 & 162 \\
& $\%$ & 77.8 & 22.2 & 180.0 \\
Total & $N$ & 145 & 39 & 100.0 \\
& $\%$ & 78.8 & 21.2 & 943 \\
\end{tabular}

Note: A chi-square test shows that differences are significant, $p<.05$. 


\section{Geographical variations in recurrent participation}

The next variable to be considered concerns the geographical dimension, and the recurrent participation among vocational teachers from different types of municipalities (Table 5). The main difference we can see here is that vocational teachers from low-populated municipalities recurrently participate to a much lower degree than those from other geographical areas. It should be noted that among all participants, the lowest degree of participation compared to geographical location (and the size of population of vocational teachers) was teachers from all large city areas (Andersson and Köpsén 2015).

\section{Variations in recurrent participation according to vocational areas}

Finally, there are significant differences in recurrent participation of vocational teachers according to the vocational area in which they teach (Table 6). Here, the difference that stands out is that teachers from the practical-aesthetical area have a much lower degree of recurrent participation than teachers from all the other vocational areas. This also applies for the general distribution of practical-aesthetical teachers' participation in the CPD initiative, except for the three large city areas (Andersson and Köpsén 2015). The vocational areas of Technology and Construction were also under-represented among all participants in the national CPD (Andersson and Köpsén 2015). However, here we can see that there is a high relative recurrence for vocational teachers from these two areas.

Table 7. Recurrent participation among male anld female vocational teachers from different types of municipalities.

\begin{tabular}{|c|c|c|c|c|}
\hline Type of municipalities & & Male & Female & Total \\
\hline \multirow[t]{2}{*}{ Three large city areas } & $N$ & 13 & 19 & 32 \\
\hline & $\%$ & 40.6 & 59.4 & 100.0 \\
\hline \multirow[t]{2}{*}{ Other large city areas } & $N$ & 49 & 11 & 60 \\
\hline & $\%$ & 81.7 & 18.3 & 100.0 \\
\hline \multirow[t]{2}{*}{ Highly populated municipalities } & $N$ & 50 & 17 & 67 \\
\hline & $\%$ & 74.6 & 25.4 & 100.0 \\
\hline \multirow[t]{2}{*}{ Low-populated municipalities } & $N$ & 9 & 1 & 10 \\
\hline & $\%$ & 90.0 & 10.0 & 100.0 \\
\hline \multirow[t]{2}{*}{ Total } & $N$ & 121 & 48 & 169 \\
\hline & $\%$ & 71.6 & 28.4 & 100.0 \\
\hline
\end{tabular}

Note: A chi-square test shows that differences are significant, $p<.001$.

Table 8. Recurrent participation among teachers from different vocational areas and types of municipalities (three groups).

\begin{tabular}{lccccc}
\hline Vocational area & & Three large city areas & Other large city areas & Other municipalities & Total \\
\hline Care & $N$ & 6 & 12 & 10 & 28 \\
& $\%$ & 21.4 & 42.9 & 35.7 & 100.0 \\
Construction & $N$ & 1 & 7 & 11 & 19 \\
& $\%$ & 5.3 & 36.8 & 57.9 & 100.0 \\
Practical-aesthetical & $N$ & 3 & 3 & 5 & 11 \\
& $\%$ & 27.3 & 27.3 & 45.5 & 100.0 \\
Service & $N$ & 20 & 3 & 36.1 & 36 \\
& $\%$ & 55.6 & 11 & 23 & 100.0 \\
Technology & $N$ & 2 & 30.6 & 63.9 & 15 \\
& $\%$ & 0.6 & 24 & 38.5 & 100.0 \\
Vehicles & $N$ & 0.0 & 61.5 & 77 & 100.0 \\
& $\%$ & 32 & 60 & 45.6 & 169 \\
Total & $N$ & 18.9 & 35.5 & 100.0 \\
& $\%$ & & &
\end{tabular}

Note: A chi-square test shows that differences are significant, $p<.001$.

\section{To sum up}

So far we have seen some distinct patterns concerning vocational teachers' recurrent participation in CPD. Teachers from low-populated municipalities 'come back' to a lower degree than in other types of municipalities. Women have a lower degree of recurrent participation. Furthermore, teachers from the practical-aesthetical area also have a lower degree of participation. In addition to this, there are (non-significant) tendencies of more recurrent participation among younger teachers, and among teachers from privately owned schools. On the other hand, there are no such distinct differences of 
recurrent participation between the other categories in the variables presented above.

\section{A focus on recurrent participation}

Finally, we will focus on the participants that participated recurrently. We consider them firstly in relation to sex and geographical and vocational areas; secondly in a logistic regression analysis in which we compare those who have participated recurrently with those who have not. It should be noted that the variable age is not included in these comparisons, as there were no significant differences identified above, nor any significant influence in the regression analysis.

\section{The relationship of sex and municipality}

If we focus on the 169 vocational teachers who participated more than once, we can make some further comparisons. When we compare male and female vocational teachers from different types of municipalities (Table 7), the results show that among the rather few women who participated more than once the highest relative participation is within the three large city areas. In all other types of municipalities, male teachers are over-represented.

Table 9. Logistic regression in reference to recurrent participation in CPD among Swedish vocational teachers.

\begin{tabular}{|c|c|c|c|}
\hline Variable & Category & $\operatorname{Exp}(B)$ & S.E. \\
\hline \multirow[t]{3}{*}{ Semester for first occasion of participation (reference = Semester 4) } & Semester 1 & $10.22^{* *}$ & 0.29 \\
\hline & Semester 2 & $1.99^{*}$ & 0.27 \\
\hline & Semester 3 & $2.31^{* *}$ & 0.27 \\
\hline Puplic/private school (reference = public) & Privately owned & $2.25^{* *}$ & 0.31 \\
\hline Sex (reference $=$ female) & Male & $2.14^{* *}$ & 0.21 \\
\hline UpSec/AE (reference = upper secondary) & Adult education & $2.67^{* *}$ & 0.33 \\
\hline \multirow[t]{3}{*}{ Type of municipality (reference = low-populated municipalities) } & Three large city areas & $2.35^{*}$ & 0.42 \\
\hline & Other large city areas & $3.42^{* *}$ & 0.38 \\
\hline & Highly populated municipalities & $2.56^{*}$ & 0.38 \\
\hline Constant & & $0.020^{* *}$ & 0.43 \\
\hline
\end{tabular}

${ }^{*} p<.05 ;{ }^{* *} p<.01$.

\section{The relationship between vocational area and municipality}

When comparing patterns of recurrent participation among vocational teachers from the different vocational areas, and in the different types of municipalities, we merged the two groups of municipalities outside the large city areas. We did so in order to identify significant differences (Table 8).

Among teachers from the vocational area of Service, the highest proportion of recurrent participation is found in the three large city areas. Those vocational teachers also have the highest number of returners in this geographical area. The same pattern also applies to teachers from the vocational area of Vehicles in relation to other large city areas. These patterns also reflect the patterns of participation in the national initiative of CPD as a whole (Andersson and Köpsén 2015).

Among participants from the Construction and Technology areas, the highest proportions of recurrent participation are found in the 'other municipalities'. In these geographical locations most returners are vocational teachers from the area of Technology. This reflects the participation in the overall CPD initiative, where teachers from this area were slightly over-represented in these other municipalities. However, it should be noted that vocational teachers from the area of Technology, as well as Construction, are under-represented in the overall CPD initiative (Andersson and Köpsén 2015).

\section{Likelihood of recurrent participation}

Logistic regression was performed to assess the impact of a number of background variables on the likelihood of recurrent participation in the CPD initiative. In should be noted that the variables of age and vocational area did not contribute significantly to the variation in recurrent participation and were not included in the model. The independent variables that had a significant influence and were included as predictors in the model were sex, publicly vs. privately owned schools, upper secondary school vs. adult education and type of municipality of teaching institution (Table 9). As mentioned, the semester for the first occasion of participation was also added as a predictor that was controlled for in the analysis. 
The model containing all included predictors was statistically significant, $\chi 2(9, \mathrm{n}=948)=104.84$, $\mathrm{p}<0.00$, indicating that the model was able to distinguish between vocational teachers who did or did not participate more than once. The model as a whole explained between $10.5 \%$ (Cox and Snell R2) and $17.2 \%$ (Nagelkerke R2) of the variance in recurrent participation, and correctly classified $81.9 \%$ of the cases.

The strongest predictor was, not unexpectedly, a first occasion of participation in semester 1 (with semester 4 as a reference-category). That is, entering the initiative early gives the teacher much more time for recurrent participation during the two-year period included in the study. However, we can see that a first occasion of participation during semester 2 means a lower odds ratio of recurrent participation than a first participation during semester 3 . This could probably be explained by changes taking place during the summer holiday, e.g. vocational teachers that leave the teacher occupation or change employer, which means new institutional and situational conditions for participation after summer.

Among the background variables, the geographical location is the strongest predictor, particularly coming from the 'other large city areas', where the low-populated municipalities form the reference category with the lowest likelihood of recurrent participation. Here, it should be noted that the regression analysis shows a difference between the 'other large city areas' and the 'highly-populated municipalities' that was not revealed when we compared categories of different types of municipalities without controlling for other variables.

In total, there were rather few vocational teachers participating in the CPD initiative from privately owned schools or from adult education (Andersson and Köpsén 2015). However, we can see that the odds ratios of recurrent participation are higher for those teachers from privately owned schools and from adult education who actually participate than for participating teachers from public schools and upper secondary schools, and the non-significant differences in rate of recurrent participation revealed above actually mean significant differences in the logistic regression where other variables are controlled for. The fact that odds ratios of recurrent participation being higher for those vocational teachers from privately owned schools and adult education who actually participate seems to be related to institutional factors. These factors reduce the likelihood of participating in this type of CPD, but when some of the teachers actually participate, they are more likely to participate more than once.

Finally, the significant difference in rate of recurrent participation between male and female vocational teachers is reflected in an odds ratio in favour of recurrent participation among male teachers.

\section{Discussion}

Reformation of Swedish vocational education imposes demands on teachers to have up-to-date knowledge about the vocations related to their vocational subjects in order to be able to strengthen the working-life connection. To support the reform efforts, vocational teachers have been offered the chance to cross the boundaries between school and work-life to participate in a national CPD initiative that targets their vocational competence. The aim of this study is to explore the recurrent participation among vocational teachers in this new CPD initiative.

It is rare that vocational teachers are given the opportunities for professional development that suit their special needs, so this chance for vocational teachers to participate in CPD activities can be seen as a new institutional offer for CPD as well as recognition of vocational teachers' dual professionalism. In Fejes and Köpsén (2014), Swedish vocational teachers pointed out hindrances to retaining their vocational identities, i.e. still being competent in relation to the vocational subject. They mentioned barriers, which could be seen as institutional, e.g. managements' lack of interest or financial support. The CPD initiative is meant to reduce such obstacles. However, as it is a new opportunity for CPD it is difficult to know if it will succeed or not. However, nearly $10 \%$ of the Swedish vocational teachers have participated over the two years included in this study. There was a similar initiative in Finland where 5\% of the vocational teachers participated in 2012 (Kumpulainen 2014), and about the same proportion of Swedish vocational teachers participated in 2013. When it comes to recurrent participation, our study shows that among the 981 vocational teachers who took part in the initiative, 169 of them had participated more than once. This means that $17.2 \%$ of the vocational teachers 'came back' after their 
first participation in the CPD activities. However, as this institutional opportunity is new there have not been so many occasions for participation yet.

The present study shows how vocational teachers' recurrent boundary-crossing and participation are distributed according to sex, age and vocational and geographical areas. Furthermore, findings show differences between those who have participated recurrently and those who only participated once. It is presumed that institutional and situational factors may influence the vocational teachers' crossing of boundaries. Also individual dispositions and motivation may have an impact on participation; however, as mentioned before, this could not be determined from the data in the present study.

The current study shows that women have a significantly lower degree of recurrent participation, i.e. a clearer difference than in the general distribution of women's participation in the CPD initiative, where the over-representation of male teachers was not significant (Andersson and Köpsén 2015). Furthermore, the high number of older teachers in the overall initiative is not seen among the recurrent participants, where there is a (non-significant) tendency for more recurrent boundary-crossing and participation among younger teachers. Here, it would have been useful to have dispositional data related to sex and age to see if there were any factors explaining these differences in participation. For example, to what extent do the differences between men and women depend on varying life situations? Furthermore, are there other factors in terms of gender differences that are reflected in uneven distribution of male and female vocational teachers in different vocational areas?

Different types of schools could imply various institutional requirements and conditions for CPD. Swedish upper secondary education has a high number of privately owned schools, although this was not mirrored in the overall participation in the new national initiative of CPD as the private schools were under-represented (Andersson and Köpsén 2015). However, examining the recurrent participation shows that vocational teachers from private schools are slightly over-represented.

As regards situational conditions for boundary-crossing, Andersson and Köpsén (2015) discussed the geographical areas' various opportunities or barriers for boundary-crossing between school and work life. Living and working outside the large city areas is seen as likely to be associated with situational opportunities for participation such as access to other types of personal and work-life relations and networks than in large cities. Andersson and Köpsén saw the over-representation of vocational teachers from the areas outside the large city areas as an indication of such a pattern. However, in the present study of recurrent participation the vocational teachers from low-populated municipalities 'came back' to a much lower degree than teachers for other geographical areas. Thus, the low degree of recurrent participation may indicate that there are barriers in low-populated areas to finding workplaces appropriate for CPD, at least for more than single occasions.

Furthermore, Andersson and Köpsén (2015) discussed whether institutional conditions such as type of work-place communities of practice and the opportunity to access them might influence the boundary-crossing between school and work life. Some communities of practice are surrounded by safety regulations and demands for certification etc., e.g. communities of practice associated with manufacturing, process industries and electricity and energy. Others are easier to obtain access to, e.g. hotels, shops and garages. The under-representation of participants from the area of Technology in the national initiative may indicate such difficulties of access. However, in the present study of recurrent participation, there is a high relative recurrence among the vocational teachers from the area of Technology. This also applies to vocational teachers from the area of Construction. If there have been any institutional barriers for crossing boundaries between school and work life in these vocational areas it seems that when you have overcome them, it is easy to return.

Moreover, another significant difference in recurrent boundary-crossing and participation between vocational areas is that teachers from the practical-aesthetical area have a lower degree of recurrent participation than teachers from other vocational areas. However, this reflects the general distribution of this group of vocational teachers' participation (Andersson and Köpsén 2015). One might guess this is a kind of work-life community of practice that is accessible. Based on the present results, this seems to be an incorrect assumption and there might be other obstacles.

An alternative explanation is that the barriers are so low in some vocational areas that institutional 
support for developing the teachers' vocational identity, i.e. to help them stay up to date in relation to the vocational subject, is not necessary for boundary-crossing. For example, it is well known that it is easy to do extra work in restaurants. This may apply to other areas as well, which could explain low interest in arranged CPD activities generally, and particularly for recurrent participation.

Furthermore, the institutional conditions relate to two contexts: institutions in the work life, and in the school system. The national initiative gives general institutional support within the school system. However, the variation in participation within and between institutions of vocational education is probably also influenced by local institutional school factors as well as local situational factors (e.g. do school management see a need for updating the vocational subject competence of the teaching staff?). Such data are not included in the present study but could have made it possible to explain to a higher degree the variation in recurrent participation.

The examination of vocational teachers' overall boundary-crossing and participation (Andersson and Köpsén 2015) as well as the present study of teachers' recurrent participation in CPD in their teaching subject have shown a number of variations in relation to vocational teachers' sex and age, in what geographical locations they work and to some extent in what vocational areas they teach. The findings raise questions that would be fruitful to investigate further, such as whether there are influencing factors related to teachers' educational background and possible formal teacher training that might facilitate boundary-crossing. Furthermore, in what ways do dispositional factors impact on vocational teachers' participation in CPD? A higher degree of recurrent participation could mean weaker boundaries between school and work life, and vice versa. Thus, there are more questions to be answered regarding the Swedish vocational teachers' need of CPD and their participation in such activities. However, the available registered data of participation is not sufficient to answer these questions.

\section{Notes}

1. The main large city areas refer to the three largest cities in Sweden, Stockholm, Gothenburg and Malmö, and their 38 suburb municipalities, 41 municipalities in total; the other large city areas refer to the other 31 large cities and their 22 suburb municipalities, 53 municipalities in total; high-populated municipalities refer to 51 commuting and 54 goods-producing municipalities and 35 other municipalities in populous regions, 140 municipalities in total; and low-populated municipalities refer to 20 rural municipalities, 16 municipalities in sparsely populated regions, and 20 tourism and visiting municipalities, 56 municipalities in total.

2. The six vocational areas include the following programmes: 1. Care: Child and Recreation, and Health and Social Care; 2. Construction: Building and Construction; and HVAC and Property Maintenance; 3. Practical aesthetical programmes: Handicraft, Natural Resource Use and the local programme of Dance; 4. Service: Business and Administration, Hotel and Tourism and Restaurant Management and Food; 5. Technology: Industrial Technology, and Electricity and Energy; and 6. Vehicles: Vehicle and Transport, and the local programme of Aircraft Technology.

\section{References}

Andersson, P., and S. Köpsén. 2015. "Continuing Professional Development of Vocational Teachers Participation in a Swedish National Initiative."Empirical Research in Vocational Education and Training 7 (7): 1-20. doi: 10.1186/s40461-015-0019-3.

Bathmaker, A.-M., and J. Avis. 2005. "Becoming a Lecturer in Further Education in England: The Construction of Professional Identity and the Role of Communities of Practice." Journal of Education for Teaching: International Research and Pedagogy 31 (1): 47-62.

Billett, S. 2011. Vocational Education. New York, NY: Springer.

Bound, H. 2011. "Vocational Education and Training Teacher Professional Development: Tensions and Context." Studies in Continuing Education 33 (2): 107-119.

Brockmann, M., L. Clarke, P. Méhaut, and C. Winch. 2008. "Competence-Based Vocational Education and Training (VET): The Cases of England and France in a European Perspective." Vocations and Learning 1 (3): 227-244.

Brockmann, M., L. Clarke, and C. Winch. 2008. "Knowledge, Skills, Competence: European Divergences in Vocational, Education and Training (VET) - The English, German and Dutch Cases." Oxford Review of Education 34 (5): 547-567. 
Cross, K. P. 1981. Adults as Learners. San Francisco, CA: Jossey-Bass.

Desjardins, R. 2015. Participation in Adult Education Opportunities: Evidence from PIAAC and Policy Trends in Selected Countries. Paper commissioned for the EFA Global Monitoring Report 2015, Education for All 2000-2015: achievements and challenges. Accessed November 24, 2015. http://unesdoc.unesco.org/images/0023/002323/232396e.pdf

Eerola, T. 2007. "Redogörelse för lärarnas arbetslivsperioder." [Report of Vocational Teachers' Work Placement Periods.] In De kunde inte tänka sig göra annat [They could not Imagine Doing Other Things], edited by M. Majuri, and T. Eerola, 55-82. Helsinki: Utbildningsstyrelsen [The Finnish National Board of Education].

Fejes, A., and S. Köpsén. 2014. "Vocational Teachers' Identity Formation through Boundary Crossing." Journal of Education and Work 27 (3): 265-283.

Frisk, T. 2014. Guide for the Implementation of Vocational Teachers' Work Placement Periods. Helsinki: The Finnish National Board of Education.

Gleeson, D., and D. James. 2007. "The Paradox of Professionalism in English Further Education: A TLC Project Perspective." Educational Review 59 (4): 451-467.

Grollmann, P. 2008. "The Quality of Vocational Teachers: Teacher Education, Institutional Roles and Professional Reality.” European Educational Research Journal 7 (4): 535-547.

Kumpulainen, T., ed. 2014. Opettajat Suomessa 2013 [Teachers in Finland 2013], Statistical report 2014:8. Helsinki: Opetushallitus [Finnish National Board of Education].

Lave, J., and E. Wenger. 1991. Situated Learning. Cambridge: Cambridge University Press.

Lloyd, C., and J. Payne. 2012. "Raising the Quality of Vocational Teachers: Continuing Professional Development in England,

Wales and Norway." Research Papers in Education 27 (1): 1-18.

Lucas, N., and L. Unwin. 2009. "Developing Teacher Expertise at Work: In-Service Trainee Teachers in Colleges of Further Education in England." Journal of Further and Higher Education 33 (4): 423-433.

Ministry of Education. 2009. Prop 2008/09:199 Högre krav och kvalitet i den nya gymnasieskolan [Higher Demands and Quality of the New Upper Secondary School]. Stockholm: Ministry of Education.

Misra, P. K. 2011. "VET Teachers in Europe: Policies, Practices and Challenges." Journal of Vocational Education \& Training 63 (1): 27-45.

Nylund, M. 2013. "Vocational Education, Class and Knowledge. A Study of Social and Political Implications of Content Organization in Vocational Education, Focusing on the Upper-secondary School Reform of 2011." PhD diss., Örebro: Örebro University.

Opetushallitus. 2014. Examensmästare, utbildningsprogram [Master of Competence-based Qualifications, Curriculum]. Helsinki: Opetushallitus [Finnish National Board of Education].

Parsons, D., J. Huges, C. Allincon, and K. Walsh. 2009. "The Training and Development of VET Teachers and Trainers in Europe." In Modernising Vocational Education and Training, Fourth Report on Vocational Education and Training Research in Europe: Synthesis Report, edited by Cedefop, 71-141. Luxembourg: Publications Office of the European Union.

Statistics Sweden. 2011. Regionala indelningar i Sverige den 1 januari 2011 [Regional Divisions in Sweden on 1 January 2011]. Örebro: Statistics Sweden.

Swedish National Agency of Education. 2014a. Accessed May 30, 2014. http://www.skolverket.se/statistikoch-utvardering/

statistik-i-tabeller/komvux/elever-och-kursdeltagare

Swedish National Agency of Education. 2014b. Bidrag för kompetensutveckling av lärare i yrkesämnen. Accessed May 30, 2014.

http://www.skolverket.se/skolutveckling/statsbidrag/yrkesutbildning/kompetensutveckling-larareyrkesamnen-1.178759\#

Wenger, E. 1998. Communities of Practice. Cambridge: Cambridge University Press.

Wheelahan, L., and G. Moodie. 2010. The Quality of Teaching in VET: Final Report and Recommendations. Melbourne: LH Martin Institute: University of Melbourne. 